\title{
Implementation of a Community-Based Exercise Program for Parkinson Patients: Using Boxing as an Example
}

\author{
Josefa Domingos $^{\mathrm{a}, \mathrm{b}}$, Danique Radder ${ }^{\mathrm{a}}$, Sara Riggare ${ }^{\mathrm{c}}$, Catarina Godinho ${ }^{\mathrm{d}}$, John Dean ${ }^{\mathrm{e}}$, \\ Mariella Graziano $^{\mathrm{f}}$, Nienke M. de Vries ${ }^{\mathrm{a}}$, Joaquim Ferreira ${ }^{\mathrm{g}, \mathrm{h}}$ and Bastiaan R. Bloem ${ }^{\mathrm{a}, *}$ \\ ${ }^{a}$ Department of Neurology, Radboud University Medical Center, Donders Institute for Brain, \\ Cognition and Behaviour, Nijmegen, The Netherlands \\ ${ }^{\mathrm{b}}$ Department of Sport and Health, Laboratory of Motor Behavior, Faculty of Human Kinetics, \\ University of Lisbon, Portugal \\ ${ }^{\mathrm{c}}$ Department for Learning, Health Informatics Centre, Informatics, Management, and Ethics, \\ Karolinska Institutet, Stockholm, Sweden \\ ${ }^{\mathrm{d}}$ Centro de Investigação Interdisciplinar Egas Moniz (CiiEM), Instituto Universitário Egas Moniz, \\ Monte de Caparica, Portugal \\ ${ }^{\mathrm{e}}$ Triad Health AI, Boulder, CO, USA \\ ${ }^{\mathrm{f}}$ Neuro-Physiotherapy Practice, Esch-sur-Alzette, Luxembourg \\ ${ }^{\mathrm{g}}$ Instituto de Medicina Molecular, Faculdade de Medicina, Universidade de Lisboa, Portugal \\ ${ }^{\mathrm{h}}$ CNS - Campus Neurológico Sénior, Torres Vedras, Portugal
}

Accepted 30 April 2019

\begin{abstract}
.
Background: Persons with Parkinson's disease (PD) benefit from continuous exercise through participation in communitybased exercise programs. However, community programs often lack PD-specific knowledge needed to provide safe and adequately dosed exercise.

Objective: To evaluate the acceptability and safety of a PD-specific boxing program in the community.

Methods: We developed specific educational resources to facilitate the boxing instructors. We also organized an educational and practical workshop for patients $(n=26)$ and instructors $(n=10)$, and assessed: (a) participants' satisfaction; (b) instructors' appreciation of the educational resources; and (c) numbers of patients interested in participating in the boxing program. After 18 months, patients and instructors completed a questionnaire evaluating: (a) participants' satisfaction; (b) adverse events; (c) facilitators and barriers; and (d) proportion of participants at follow-up.

Results: Twenty-six persons with PD (62\% men) and 10 boxing instructors participated in the workshop. $81 \%$ of patients and $80 \%$ of instructors were very satisfied. Instructors found the educational materials "very helpful" (60\%) or "helpful" (40\%). Patients expressed a clear interest $(54 \%)$ or possible interest $(46 \%)$ in the program. We initiated classes with 10 participants. At 18-months follow-up, the program consisted of four boxing sessions/week, led by three instructors, with 40 participants. Seventeen patients responded to the questionnaire at follow-up. Participants were "very satisfied" (53\%), "satisfied" (35\%) and neither satisfied nor unsatisfied (12\%) with the program. Adverse effects were mild (e.g., muscle aches). Transportation and physical disability were the main barriers for participation.

Conclusions: The boxing program was well-received, with increasing numbers of participants at 18 months. The educational resources can support boxing instructors participating in current and future boxing classes being delivered in the community.
\end{abstract}

Keywords: Boxing training, community exercise, Parkinson's disease, physiotherapy

\footnotetext{
${ }^{*}$ Correspondence to: Professor Bas Bloem, Department of Neurology (935), Radboud University Medical Centre, PO Box 9101,
} 


\section{INTRODUCTION}

Parkinson's disease (PD) is a progressive neurodegenerative movement disorder that has a tremendous impact on activities of daily life and social participation $[1,2]$. Physiotherapy and exercise can improve physical functioning [3, 4]. However, continuous exercise is needed to maintain results and to promote a physically active lifestyle [5]. Compliance with such prolonged programs remains a critical challenge.

One possible solution to promote a sustained adherence to exercise is through participation in different non-traditional types of group communitybased exercise programs. Evidence supporting such programs for persons with $\mathrm{PD}$ is growing, with examples in dance $[6,7]$, boxing $[8,9]$, Nordic walking [10, 11], tai chi [12, 13], Qigong [14], and aquatic exercise $[15,16]$, among others. Despite these positive effects, implementation of community-based exercise programs is often hampered by limited information regarding the exact intervention, the delivery mode and lack of specific knowledge about PD that is needed to provide safe and adequately-dosed exercise programs tailored to the specific abilities of patients $[3,17,18]$.

As community-based exercise programs in PD begin to spread globally, some fundamental questions arise. How should exercises be adapted to the capabilities of people with PD? Who should be responsible for developing as well as implementing these exercise programs (i.e., specialized physiotherapist, exercise instructor)? Is a community-based exercise instructor without a longstanding history in treating large numbers of PD patients capable of providing exercise to PD patients safely? Here, we propose a scalable method for implementation by presenting a community-based boxing program specifically designed for people with PD that was delivered by generically trained boxing instructors who received clinical education and supervision under an expert physiotherapist. Boxing was selected because it is a promising new intervention that is currently very popular among patients in the PD community. Boxing has been shown to be safe and feasible [8] and more effective than conventional group exercise in improving gait velocity and endurance [9]. We present the implementation of this PD-specific, communitybased boxing program and evaluate this program on the following items: 1) adherence (based on number of people participating); 2) acceptability (based on satisfaction level, perceived benefits and barriers and facilitators); and 3) safety (based on the number and types of problems identified during the program) at 18-months follow-up.

\section{METHODS}

\section{Design}

This study uses a qualitative descriptive design to address the implementation of a boxing program in a community setting. The following steps were taken: development of educational resources, organizing an educational workshop, and 18-month follow-up evaluation.

\section{Step 1: Development of educational resources}

First, we developed a toolbox including specific educational resources to support boxing instructors in delivering PD-specific classes. The toolbox was developed based on scientific evidence [3, 8, 9] in combination with expert opinion from (a) one expert physiotherapist [19]; (b) exercise instructors with experience in boxing $(n=3)$; and (c) persons with PD who currently participated in boxing classes $(n=6)$. Three types of educational resources were developed and included in the toolbox: 1) an "Outline for Group Boxing Training" specific to PD (Supplementary Material); 2) example of the structure of a PD-specific boxing class (Supplementary Material) 2 ); and 3) exercise videos. The outline consisted of recommendations in the following key areas: 1) inclusion and exclusion criteria; 2) assessments; 3 ) boxing goals; 4) core areas and principles of the intervention (e.g., use of amplitude-based movements), and content of a class; 5) progressing the level of difficulty; 6) PD-specific problems that may arise while boxing; 7) group size; 8) emergencies in PD; 9) organization of the class; and 10) adaptations to the gym.

\section{Step 2: Providing and evaluating the educational workshops}

Second, we organized an educational workshop with sessions for future instructors (certified boxing trainers) and with sessions separately for patients, who were recruited by the local Parkinson Patient Association. All sessions in the 2-day workshop were delivered by a PD expert physiotherapist with boxing training and experience in building community programs, accompanied by a person with Parkinson (SR) who gave input from the patient perspective. 
The first educational session (4 hours in the morning) was provided solely to the instructors and focused on providing them with key information regarding PD as well as details regarding the core areas and principles of the intervention. Specifically, instructors learned: (a) how to perform baseline evaluations; (b) how to provide exercises safely and effectively (with respect to $\mathrm{PD}$-specific problems); and (c) how to recognize red flags such as medication interactions and other emergency situations during training. The importance of assessing fall risks and providing instructions in a manner that would prevent falls in people with PD was highlighted. Instructors were taught to identify people at risk of falling using a brief assessment. Instructors were then invited to participate in the patient sessions organized in the afternoon, allowing them to experience an example of a boxing session with patients, supporting at-risk patients and encouraging them at the individual stations. For the patient sessions, people with PD were organized into 3 groups with a maximum of 10 participants. Each group came in at different times throughout 2 days. The sessions for the patient included one hour of education on the potential benefits for PD followed by a one-hour practical session. Details of the educational sessions given to the instructors and patients are shown in Table 1.
Importantly, care partners and other family members were also invited to participate in the patient sessions (both the educational and the training sessions) to provide support, encouragement and enhance adherence [20].

For the practical boxing session, participants completed an informed consent form and completed two physical tests (Sit to Stand and Timed-Up-and-Go) as a rapid screening of fall risks. The Timed Up and Go Test [21] provides detailed information on walking speed a during functional mobility task. Fall risk is defined based upon the time it takes to perform the test, with a cut-off for high risk set at $\geq 13.5$ seconds. The Five times Sit to Stand Test [22] is a test that measures the time needed to rise from a 43-centimetre chair. It is used to assess balance when performing transfers. Risk of falling is set as $\geq 16$ seconds.

At the end of the workshop, patients were asked to rate their satisfaction on a brief self-administered questionnaire with 3 questions: 1) "How satisfied are you with participating in the workshop?" $(1=$ Very satisfied; $2=$ Satisfied; $3=$ Neither satisfied or unsatisfied; $4=$ Dissatisfied), 2) "Did any problems arise during the workshop?", and 3) "Would you like to participate in a boxing training program?" (yes, no or maybe). The questionnaire was purposely short to reduce patient burden after a long day [23, 24]. Instructors were also asked to rate their level

Table 1

Goals, actions, and safety issues of the educational sessions for the instructors and patients

\begin{tabular}{|c|c|c|}
\hline \multicolumn{3}{|c|}{ Table 1 - Educational workshop } \\
\hline & For boxing Instructors & For people with PD \\
\hline Main Aim & $\begin{array}{l}\text { To deliver effective and safe application of } \\
\text { boxing training in PD. }\end{array}$ & $\begin{array}{l}\text { To allow patients to experience the beneficial } \\
\text { effects of exercising with boxing and to } \\
\text { receive social support from fellow patients. }\end{array}$ \\
\hline \multirow[t]{2}{*}{ Actions } & $\begin{array}{l}\text { (1) A 4-hour educational session covering: (a) } \\
\text { general information on PD, (b) the benefits of } \\
\text { using boxing in PD, (c) video demonstrations } \\
\text { of adapted exercises, (d) examples of ways to } \\
\text { structure and progress classes, and (e) going } \\
\text { through the key areas defined in the developed } \\
\text { toolkit. }\end{array}$ & $\begin{array}{l}\text { (1) A 30-minute educational session covering: } \\
\text { (a) the beneficial effects of physical activity; } \\
\text { (b) the potential benefits of boxing in PD; (c) } \\
\text { potential barriers to participate in boxing and } \\
\text { possible solutions; and (d) education about the } \\
\text { importance of safety during trainings. }\end{array}$ \\
\hline & $\begin{array}{l}\text { (2) Participating in a 1-hour boxing session with } \\
\text { patients. }\end{array}$ & $\begin{array}{l}\text { (2) A 1-hour boxing session led by } \\
\text { physiotherapist with support from boxing } \\
\text { instructors. }\end{array}$ \\
\hline Safety Notes & $\begin{array}{l}\text { Assessing fall risk and preventing falls was } \\
\text { strongly reinforced and instructors were } \\
\text { taught to identify patients at risk with a brief } \\
\text { assessment using: history of falls in the past } \\
12 \text { months and the Timed Up \& Go test (TUG) } \\
\text { [3]. }\end{array}$ & $\begin{array}{l}\text { Before the boxing session, patients gave } \\
\text { informed consent for participation, were asked } \\
\text { if they had fallen in the last } 12 \text { months and } \\
\text { completed the TUG test for a quick screening } \\
\text { of fall risk. Patients identified at risk of falling } \\
\text { were provided with additional support by } \\
\text { boxing instructors, care partners or volunteers } \\
\text { (60+ aged non-PD boxing training } \\
\text { participants). }\end{array}$ \\
\hline
\end{tabular}

PD, Parkinson's disease; Patients, person with Parkinson's disease: TUG, Timed Up \& Go test. 
of satisfaction with the workshop ( $1=$ Very satisfied; 2 = Satisfied; $3=$ Neither satisfied or unsatisfied; 4 = Dissatisfied); how helpful they found the educational materials $(1=$ Not helpful at all; $2=$ Helpful; $3=$ Very helpful; $4=$ Extremely helpful) and if there were any concerns or additional comments.

\section{Step 3:18-month follow-up assessment}

The boxing program was then delivered for 18 months before reassessment. The boxing program was delivered in a group format, but volunteers provided personalized support to people at risk of falling. Instructors could contact an expert physiotherapist at any time for clarifications or on any issues related to the program via email or Skype calls (clinical mentorship). After 18 months, we first assessed the adherence by looking into how many patients started the program immediately after the workshop, how many of these were still following the program after 18 months, and the total amount of patients that were in the program at 18 months. Second, we studied the acceptability by patients based on the response on a questionnaire given to patients (those that participated in the initial workshop and also patients that started afterwards) during the sessions regarding: 1) satisfaction at 18 months; and 2) the perceived barriers and facilitators for participating in this community boxing program. Finally, we assessed safety issues by asking about the types of problems reported by participants and instructors during boxing training.

\section{RESULTS}

\section{Educational workshop}

\section{Participants}

Twenty-six persons with PD (62\% men) and 10 boxing instructors participated in the workshop. Three sessions with patients were organized (3 groups with $\leq 10$ patients). All participants ambulated independently; however, $3(3 / 26 ; 12 \%)$ patients had an increased risk of falling based on the fall screening (Table 2). To reduce the fall risk during the workshop, each of these patients were supported by a volunteer.

\section{Acceptability}

High satisfaction with the workshop was reported by five Patients $(5 / 26 ; 19 \%)$ scoring "satisfied" and 21 $(21 / 26 ; 81 \%)$ reporting to be "very satisfied". Overall, 14 patients $(14 / 26 ; 54 \%)$ said that they would be interested in participating in the program and 12 Patients
(12/26; 46\%) indicated a possible interest. Patients identified some general (non-PD specific) issues during the workshop, namely 1) feeling discomfort due to excessive sweating from wearing the gloves; and 2) experiencing more stress during the paired activities. They also indicated that involving care partners would likely enhance their attendance.

Eight instructors were (8/10; 80\%) "very satisfied" with the workshop and two were "satisfied" (2/10; $10 \%)$. Instructors found the educational resources either "helpful" $(4 / 10 ; 40 \%)$ or "very helpful" (6/10; $60 \%)$.

Safety

All participants completed the workshop without any serious adverse events, except for one patient experiencing anxiety while coming down the stairs. As such, the gym stairs were adjusted immediately by applying visual cues (white tape) on the stairs to improve visual contrast, facilitating movement and increasing general sense of safety. Instructors also identified some concerns regarding their lack of PDspecific expertise and on how to help patients navigate through difficult environments, such as the stairs.

\section{8-month follow-up assessment}

\section{Adherence/participation}

The boxing program (Narva Boxningklubb) initiated PD boxing classes one week after the workshop with 10 out of the 26 patients participating in the workshop (38\%). Initially, two boxing classes per week were offered for these 10 patients.

At 18-month follow-up, the number of participants had grown to 40 people with PD, including eight of the 10 patients that initially started $(80 \%)$ and participated in the workshop 18 months before. The Narva gym offers four boxing sessions per week provided by three instructors (out of the 10 trained instructors $(30 \%))$. The other trained instructors had meanwhile begun to participate in 13 other boxing classes across Sweden, serving up to 250 PD patients.

\section{Acceptability}

Seventeen participants (out of 40 participating) and all instructors responded to the follow-up questionnaires. Participants indicated that they were very satisfied $(9 / 17 ; 53 \%)$, satisfied $(6 / 17 ; 35 \%)$ and neither satisfied nor unsatisfied $(2 / 17 ; 12 \%)$. None of the participants were unsatisfied. Self-reported problems, facilitators and barriers are presented in Table 3 . Transportation and physical disability were the most 
Table 2

Timed Up \& Go and Sit to Stand test scores before and after the workshop

\begin{tabular}{|c|c|c|c|}
\hline Participant & $\begin{array}{l}\text { History of falling last } 12 \\
\text { months (yes }=1 ; \text { no }=0 \text { ) }\end{array}$ & $\begin{array}{l}\text { Sit-to-stand pre }(\geq 16 \\
\text { at risk of falling) }\end{array}$ & $\begin{array}{c}\text { TUG pre (risk if) score } \\
\geq 13.5 \text { seconds }\end{array}$ \\
\hline 1 & 0 & 10.82 & 6.02 \\
\hline 2 & 0 & 6.8 & 6.3 \\
\hline 3 & 0 & 8.37 & 6.5 \\
\hline 4 & 0 & 12.63 & 8.05 \\
\hline 5 & 0 & 13.33 & 9.43 \\
\hline 6 & 0 & 11.43 & 7.88 \\
\hline 7 & 1 & 12.1 & 14.26 \\
\hline 8 & 0 & 7.61 & 5.86 \\
\hline 9 & 0 & 15.21 & 9.15 \\
\hline 10 & 0 & 13.06 & 9.23 \\
\hline 11 & 0 & 13.43 & 9.65 \\
\hline 12 & 0 & 6.73 & 7.48 \\
\hline 13 & 1 & 15.86 & 13.53 \\
\hline 14 & 0 & 7.6 & 7.26 \\
\hline 15 & 0 & 10.61 & 9.09 \\
\hline 16 & 0 & 8.56 & 6.35 \\
\hline 17 & 0 & 9.35 & 7.38 \\
\hline 18 & 0 & 7.91 & 6.78 \\
\hline 19 & 0 & 9.38 & 6.36 \\
\hline 20 & 0 & 6.76 & 4.48 \\
\hline 21 & 0 & 11.28 & 6.34 \\
\hline 22 & 0 & 12.05 & 9.87 \\
\hline 23 & 0 & 6.43 & 6.38 \\
\hline 24 & 1 & 11.41 & 13.92 \\
\hline 25 & 0 & 6.91 & 6.08 \\
\hline \multirow[t]{2}{*}{26} & 0 & 6.3 & 5.81 \\
\hline & & Mean $=10.07(S D+/-2.86)$ & Mean $=8.05(S D+/-2.57)$ \\
\hline
\end{tabular}

common barriers and facilitators reported. During the 18 months, the expert physiotherapist was consulted twice by instructors regarding training intensity and potential new activities.

\section{Safety}

At follow-up, instructors reported that (a) no major problems were encountered during the sessions; (b) patients needed to be monitored continuously (especially during transition among the exercise stations), and (c) some participants needed more assistance and time for learning than others.

\section{DISCUSSION}

PD-specific community exercise programs have recently gained considerable attention as a means to achieve long-term exercise adherence in PD. However, evidence regarding how these programs should be developed, delivered and implemented is still limited. Here we describe the implementation of a PD-specific community boxing program, as an example of this fast-developing field. Our findings indicate that the program was overall well-received and accepted by persons with PD, both during the initial workshop and at 18-months follow-up. Initial training for the boxing instructors with a specifically developed toolbox was perceived as useful and may serve as an example when developing similar programs.

We believe that several factors contributed to the success of this boxing program. First, we used an exercise modality that is gaining popularity within the PD community [8,9]. Apart from being satisfied with the workshop, $38 \%$ of patients started the program immediately after the workshop, and 40 patients took part in the program at 18 months follow-up. These results are in agreement with other studies showing a desire to participate in PD-specific community exercise programs [25]. Alongside previously published preliminary evidence on the safety, feasibility and effectiveness of boxing to improve balance, mobility and endurance, boxing is consistently highly regarded by participants in all these studies $[8,9]$. In addition to its physical component, boxing is also cognitively demanding (e.g., memorizing the boxing combinations, quick decision-making tasks, dealing with the busy environments) [26, 27]. Given the importance of cognitive processes in maintaining balance and reducing falls, programs that include 
Table 3

Patient satisfaction with the boxing program and perceived facilitators \& barriers at 18-month follow-up

\begin{tabular}{|c|c|c|c|c|c|}
\hline Participant & $\begin{array}{l}\text { Duration of } \\
\text { participation } \\
\text { (months) }\end{array}$ & $\begin{array}{l}\text { Problems or adverse events } \\
\text { that occurred during the } \\
\text { trainings }\end{array}$ & Facilitators to participate & Barriers to participate & $\begin{array}{c}\text { Level of } \\
\text { satisfaction } \\
\text { with } \\
\text { participation * }\end{array}$ \\
\hline 1 & 10 & $\begin{array}{l}\text { 'Neck pain, but I am careful } \\
\text { and doing better now' }\end{array}$ & None & 'Knee and neck pain' & 1 \\
\hline 2 & 1 & None & 'Good location to get to' & $\begin{array}{l}\text { 'Difficult to combine with } \\
\text { work hours and the } \\
\text { training is not } \\
\text { personalized enough' }\end{array}$ & 3 \\
\hline 3 & 12 & $\begin{array}{l}\text { 'None, just experience } \\
\text { muscle pain after training; }\end{array}$ & 'Transportation is easy' & None & 1 \\
\hline 4 & 2,5 & Knee pain & 'Feeling that exercises helps' & None & 1 \\
\hline 5 & 8 & None & None & 'No care partner support' & 2 \\
\hline 6 & 10 & None & $\begin{array}{l}\text { 'Not needing help getting to and } \\
\text { from the sessions' }\end{array}$ & None & 1 \\
\hline 7 & 6 & None & None & None & 1 \\
\hline 8 & 8 & 'sense of feeling unsafe' & None & 'Balance problems' & 2 \\
\hline 9 & 8 & None & 'Benefits of exercise' & None & 2 \\
\hline 10 & 2.5 & 'Difficult to say' & 'Having had DBS' & Traveling & 2 \\
\hline 11 & 3 & None & 'Feeling well with the exercises' & None & 1 \\
\hline 12 & 4 & None & 'Able to train during work hours' & None & 2 \\
\hline 13 & 6 & None & None & 'Physical difficulties' & 2 \\
\hline 14 & 18 & None & 'Transportation is easy' & 'Physical difficulties' & 1 \\
\hline 15 & 6 & None & None & 'Lack of transport' & 3 \\
\hline 16 & 18 & None & 'Makes me reduce my medication' & None & 1 \\
\hline 17 & 5 & None & None & None & 1 \\
\hline
\end{tabular}

*1 = Very satisfied; 2 = Satisfied; 3 = Neither satisfied nor unsatisfied; 4 = Unsatisfied.

cognitive components may have additional benefits over exercise programs that are solely physical, such as pure aerobic training by running on a treadmill [28, 29]. Indeed, the V-time study showed that multimodal training-immersing patients in a three-dimensional virtual reality environment while exercising on a treadmill demonstrated that the multimodal training afforded greater benefits (in terms of fall prevention) than treadmill walking alone [30].

Second, we believe that the collaboration between physiotherapist/clinicians and boxing instructors played a significant role in the success of this program. Access to an exercise instructor with PDspecific expertise is not always available. Enhancing the expertise of community-based exercise instructors will therefore improve access to safe and effective community-based exercise programs for patients with PD. While instructors initially highlighted concerns about their lack of knowledge about PD, they were also keen to learn. The workshop allowed them to learn about the typical signs and symptoms of $\mathrm{PD}$, and how to handle the specific limitations of PD patients during an exercise program (e.g., risk of falls, or difficulties with handling multiple tasks simultaneously). We believe that just as, for example, physiotherapists [24, 31, 32], greater levels of
PD-specific expertise among boxing instructors will improve both the benefits and the safety of the exercise program. We thus argue that with respect to safety, generically trained instructors who provide boxing, dance or other activities to people with PD should deliver their interventions in close collaboration with other health care providers that have PD-specific expertise. This expertise also enables instructors to recognize specific limitations that may warrant an adequate referral to appropriate healthcare professionals when necessary [3,33]. For example, previously undetected freezing may come to light during the exercise classes, which would usually merit referral to a neurologist or PD physiotherapist to deliver dedicated treatments for freezing [34]. We believe that the collective involvement of both boxing instructors, physiotherapists as well as patients in developing the educational resources enhanced their usability.

Third, providing a workshop for patients may have positively contributed to motivate them to participate in the program $[35,36]$. This session was designed to inform participants about the benefits of boxing as exercise in PD. Also, the workshop allowed participants to experience the beneficial effects of social support and motivation from fellow patients, while 
also seeing that they were able to successfully perform the exercises and tasks, increasing self-efficacy $[37,38]$. Participants were assessed for fall risk to guarantee additional support for those at risk of falling during the workshop (a strategy that was reinforced to boxing instructors to use for future inclusion and safety issues). The involvement of care partners was perceived to be helpful and was even suggested by patients to improve future attendance. Also, the disease-specific and boxing knowledge of the leading physiotherapist allowed for adequate replies to all questions, adaptation of the exercises to the groups' needs and quick action on problems that arose. All of these environmental aspects may have contributed to overall patient satisfaction and motivation for future adherence. Similarly, in a study on dancing, persons with PD perceived teaching methods and environmental factors as the most relevant facilitating factors when undertaking a dance class [39].

This study is not without limitations. The underlying reasons for not initiating, dropping out or being absent were not assessed and could be critical to improve long-term adherence [36, 40]. At 18 months follow-up, several barriers and facilitators for participation were identified, mainly related to transportation, class time, physical disabilities, and the content of the program (e.g., not being personalized enough). This is in line with previous research on barriers and facilitators for exercise in PD [36, 40, 41]. As the disease progresses, transportation difficulties can increase significantly due to difficulties in driving $[42,43]$ and difficulties in using public transportation. Because of these reasons, people with PD can ultimately become dependent on their caregivers for travel. However, many of these caregivers have similar age-related issues impacting their ability to drive, further complicating the problem. Travel support (possibly via volunteer initiatives) could help reduce this barrier.

In addition, we did not collect data on exercise intensity and volume of the training, even though these are important components of any training program. Gathering information on those components plus standardized assessments on fitness status/physical functioning are essential to interpreting the mechanisms underlying the effectiveness of an exercise program. However, our primary aim was to assess the acceptability and safety and therefore we did not collect such data. Another argument to consider is that in busy gyms, there may not always be enough time to perform careful assessments. We argue that having pre-program and periodic re- assessment consultations with a clinical therapist may support a better screening of fitness status, and that a periodic individualized assessment of participants may ensure better safety, while also creating an opportunity to set and adjust the intensity and volume of training, to set personalized goals and continuously adjust the program to the needs of each participant.

Adjustment of scheduled class times can make them more appropriate for patients who are still working may further improve the program. Additionally, we included participants that self-enrolled through the Parkinson Association, possibly creating a bias in the types of patients that participated. Referrals from other sources (e.g., physicians, physiotherapist, advocacy institutions) can be guided by specific referral criteria that promote integration of patients subgroups that may better benefit [33]. Notably, even though participation of individuals with cognitive impairment in exercise programs is often perceived as not feasible [44], it remains important to determine if they can participate with additional resources (e.g., volunteers or caregiver support). In our program, a volunteer-run initiative guaranteed safety to individuals with risk of falling and this strategy could also be applicable to people with cognitive impairment. This may constitute an important future line of research. Further research is needed to test the effectiveness of this program in a randomized controlled trial with different time points for follow-up assessments. Finally, a detailed process analysis may help to better understand the reasons for not attending, who to include, when the patients start getting better, what ongoing teaching methods to use and how to assess the continuous educational needs of instructors. These assessments are not only relevant to assess the program implementation and to provide feedback to participants, but also to show a benefit to those providing funding for such programs.

\section{Conclusion}

People with PD indicate a desire to participate in specialized programs but providing and maintaining safe, efficient and cost-effective community-based exercise program for PD poses many challenges. Enhancing the expertise of community-based exercise instructors and developing a closer collaboration with other health care providers can be crucial factors to guarantee an optimal quality of the exercise intervention. Our boxing program was well-received, with increasing numbers of participants at 18 months. The educational resources can support boxing instruc- 
tors participating in current and future boxing classes being delivered in the community.

\section{ACKNOWLEDGMENTS}

The authors are grateful to the people who volunteered to participate in this program (persons with Parkinson's disease, boxing instructors and volunteers). A special thank you to SR for her initiative and contributions to the program. The Radboud university medical center Nijmegen was supported by a center of excellence grant of the Parkinson's Foundation.

\section{CONFLICT OF INTEREST}

Bastiaan R. Bloem currently serves as Associate Editor for the Journal of Parkinson's Disease, has received honoraria from serving on the scientific advisory board for Zambon and Kyowa Kirin, has received fees for speaking at conferences from AbbVie, Zambon and Bial, and has received research support from the Netherlands Organization for Scientific Research, the Michael J Fox Foundation, UCB, AbbVie, the Stichting Parkinson Fonds, the Hersenstichting Nederland, the Parkinson's Foundation, Verily Life Sciences, the Topsector Life Sciences and Health, and the Parkinson Vereniging.

\section{SUPPLEMENTARY MATERIAL}

The supplementary material is available in the electronic version of this article: http://dx. doi.org/10.3233/JPD-191616.

\section{REFERENCES}

[1] Shulman LM, Gruber-Baldini AL, Anderson KE, Vaughan CG, Reich SG, Fishman PS, Weiner WJ (2008) The evolution of disability in Parkinson disease. Mov Disord 23, 790-796.

[2] Chiong-Rivero H, Ryan GW, Flippen C, Bordelon Y, Szumski NR, Zesiewicz TA, Vassar S, Weidmer B, Garcia RE, Bradley M, Vickrey BG (2011) Patients' and caregivers' experiences of the impact of Parkinson's disease on health status. Patient Relat Outcome Meas 2011, 57-70.

[3] Keus SHJ, Munneke M, Graziano M (2014) European Physiotherapy Guideline for Parkinson's Disease. KNGF/ParkinsonNet, https://www.parkinsonnet.nl/media/ 15336569/addendum_evidence_engelstalig_kngf_richtlijn_ ziekte_van_parkinson.pdf

[4] Bloem BR, de Vries NM, Ebersbach G (2015) Nonpharmacological treatments for patients with Parkinson's disease. Mov Disord 30, 1504-1520.

[5] Kwakkel G, de Goede CJ, van Wegen EE (2007) Impact of physical therapy for Parkinson's disease: A critical review of the literature. Parkinsonism Relat Disord 13(Suppl 3), S478-487.

[6] Hackney ME, Kantorovich S, Levin R, Earhart GM (2007) Effects of tango on functional mobility in Parkinson's disease: A preliminary study. J Neurol Phys Ther 31, 173-179.

[7] Duncan RP, Earhart GM (2012) Randomized controlled trial of community-based dancing to modify disease progression in Parkinson disease. Neurorehabil Neural Repair 26, 132143.

[8] Combs SA, Diehl MD, Staples WH, Conn L, Davis K, Lewis N, Schaneman K (2011) Boxing training for patients with Parkinson disease: A case series. Phys Ther 91, 132-142.

[9] Combs SA, Diehl MD, Chrzastowski C, Didrick N, McCoin B, Mox N, Staples WH, Wayman J (2013) Communitybased group exercise for persons with Parkinson disease: A randomized controlled trial. NeuroRehabilitation 32, 117124.

[10] van Eijkeren FJ, Reijmers RS, Kleinveld MJ, Minten A, Bruggen JP, Bloem BR (2008) Nordic walking improves mobility in Parkinson's disease. Mov Disord 23, 2239-2243.

[11] Monteiro EP, Franzoni LT, Cubillos DM, de Oliveira Fagundes A, Carvalho AR, Oliveira HB, Pantoja PD, Schuch FB, Rieder CR, Martinez FG, Peyre-Tartaruga LA (2017) Effects of Nordic walking training on functional parameters in Parkinson's disease: A randomized controlled clinical trial. Scand J Med Sci Sports 27, 351-358.

[12] Hackney ME, Earhart GM (2008) Tai Chi improves balance and mobility in people with Parkinson disease. Gait Posture 28, 456-460.

[13] Choi HJ (2016) Effects of therapeutic Tai chi on functional fitness and activities of daily living in patients with Parkinson disease. J Exerc Rehabil 12, 499-503.

[14] Schmitz-Hubsch T, Pyfer D, Kielwein K, Fimmers R, Klockgether T, Wullner U (2006) Qigong exercise for the symptoms of Parkinson's disease: A randomized, controlled pilot study. Mov Disord 21, 543-548.

[15] Perez-de la Cruz S, Garcia Luengo AV, Lambeck J (2016) Effects of an Ai Chi fall prevention programme for patients with Parkinson's disease. Neurologia 31, 176-182.

[16] Kurt EE, Buyukturan B, Buyukturan O, Erdem HR, Tuncay F (2018) Effects of Ai Chi on balance, quality of life, functional mobility, and motor impairment in patients with Parkinson's disease. Disabil Rehabil 40, 791-797.

[17] Aminoff MJ, Christine CW, Friedman JH, Chou KL, Lyons KE, Pahwa R, Bloem BR, Parashos SA, Price CC, Malaty IA, Iansek R, Bodis-Wollner I, Suchowersky O, Oertel WH, Zamudio J, Oberdorf J, Schmidt P, Okun MS, National Parkinson Foundation Working Group on Hospitalization in Parkinson's Disease (2011) Management of the hospitalized patient with Parkinson's disease: Current state of the field and need for guidelines. Parkinsonism Relat Disord 17, 139-145.

[18] Ahlskog JE (2014) Parkinson disease treatment in hospitals and nursing facilities: Avoiding pitfalls. Mayo Clin Proc 89, 997-1003.

[19] Nijkrake MJ, Keus SH, Oostendorp RA, Overeem S, Mulleners W, Bloem BR, Munneke M (2009) Allied health care in Parkinson's disease: Referral, consultation, and professional expertise. Mov Disord 24, 282-286.

[20] Cress ME, David M. Buchner, Thomas Prohaska, James Rimmer, Marybeth Brown, Carol Macera, Loretta DePietro, Chodzko-Zajko W (2004) Physical activity programs and behavior counseling in older adult populations. Med Sci Sports Exerc 36, 1997-2003. 
[21] Podsiadlo D, Richardson S (1991) The timed "Up \& Go": A test of basic functional mobility for frail elderly persons. $J$ Am Geriatr Soc 39, 142-148.

[22] Whitney SL, Wrisley DM, Marchetti GF, Gee MA, Redfern MS, Furman JM (2005) Clinical measurement of sit-to-stand performance in people with balance disorders: Validity of data for the Five-Times-Sit-to-Stand Test. Phys Ther 85, 1034-1045.

[23] Hackney ME, Earhart GM (2009) Effects of dance on movement control in Parkinson's disease: A comparison of Argentine tango and American ballroom. J Rehabil Med 41, 475-481.

[24] Shanahan J, Morris ME, Bhriain ON, Volpe D, Richardson M, Clifford AM (2015) Is Irish set dancing feasible for people with Parkinson's disease in Ireland? Complement Ther Clin Pract 21, 47-51.

[25] O'Brien M, Dodd KJ, Bilney B (2008) A qualitative analysis of a progressive resistance exercise programme for people with Parkinson's disease. Disabil Rehabil 30, 1350-1357.

[26] Heyn P, Abreu BC, Ottenbacher KJ (2004) The effects of exercise training on elderly persons with cognitive impairment and dementia: A meta-analysis. Arch Phys Med Rehabil 85, 1694-1704.

[27] Uc EY, Doerschug KC, Magnotta V, Dawson JD, Thomsen TR, Kline JN, Rizzo M, Newman SR, Mehta S, Grabowski TJ, Bruss J, Blanchette DR, Anderson SW, Voss MW, Kramer AF, Darling WG (2014) Phase I/II randomized trial of aerobic exercise in Parkinson disease in a community setting. Neurology 83, 413-425.

[28] Wu T, Hallett M (2005) A functional MRI study of automatic movements in patients with Parkinson's disease. Brain 128, 2250-2259.

[29] Hausdorff JM, Doniger GM, Springer S, Yogev G, Simon ES, Giladi N (2006) A common cognitive profile in elderly fallers and in patients with Parkinson's disease: The prominence of impaired executive function and attention. Exp Aging Res 32, 411-429.

[30] Mirelman A, Rochester L, Maidan I, Del Din S, Alcock L, Nieuwhof F, Rikkert MO, Bloem BR, Pelosin E, Avanzino L, Abbruzzese G, Dockx K, Bekkers E, Giladi N, Nieuwboer A, Hausdorff JM (2016) Addition of a non-immersive virtual reality component to treadmill training to reduce fall risk in older adults (V-TIME): A randomised controlled trial. Lancet 388, 1170-1182.

[31] Hirsch MA (2009) Community-based rehabilitation for Parkinson's disease: From neurons to neighborhoods. Parkinsonism Relat Disord 15(Suppl 3), S114-117.

[32] Hirsch MA, Iyer SS, Englert D, Sanjak M (2011) Promoting exercise in Parkinson's disease through community-based participatory research. Neurodegener Dis Manag 1, 365377.
[33] Domingos J, Coelho M, Ferreira JJ (2013) Referral to rehabilitation in Parkinson's disease: Who, when and to what end? Arq Neuropsiquiatr 71, 967-972.

[34] Nonnekes J, Snijders AH, Nutt JG, Deuschl G, Giladi N, Bloem BR (2015) Freezing of gait: A practical approach to management. Lancet Neurol 14, 768-778.

[35] Speelman AD, van Nimwegen M, Bloem BR, Munneke M (2014) Evaluation of implementation of the ParkFit program: A multifaceted intervention aimed to promote physical activity in patients with Parkinson's disease. Physiotherapy 100, 134-141.

[36] Ellis T, Boudreau JK, DeAngelis TR, Brown LE, Cavanaugh JT, Earhart GM, Ford MP, Foreman KB, Dibble LE (2013) Barriers to exercise in people with Parkinson disease. Phys Ther 93, 628-636.

[37] Ellis T, de Goede CJ, Feldman RG, Wolters EC, Kwakkel G, Wagenaar RC (2005) Efficacy of a physical therapy program in patients with Parkinson's disease: A randomized controlled trial. Arch Phys Med Rehabil 86, 626-632.

[38] King LA, Wilhelm J, Chen Y, Blehm R, Nutt J, Chen Z, Serdar A, Horak FB (2015) Effects of group, individual, and home exercise in persons with Parkinson disease: A randomized clinical trial. J Neurol Phys Ther 39, 204-212.

[39] Demers M, Thomas A, Wittich W, McKinley P (2015) Implementing a novel dance intervention in rehabilitation: Perceived barriers and facilitators. Disabil Rehabil 37 , 1066-1072.

[40] Rhodes RE, Martin AD, Taunton JE, Rhodes EC, Donnelly M, Elliot J (1999) Factors associated with exercise adherence among older adults. An individual perspective. Sports Med 28, 397-411.

[41] Aas RW, Grotle M (2007) Clients using community occupational therapy services: Sociodemographic factors and the occurrence of diseases and disabilities. Scand J Occup Ther 14, 150-159.

[42] Uc EY, Rizzo M, O'Shea AMJ, Anderson SW, Dawson JD (2017) Longitudinal decline of driving safety in Parkinson disease. Neurology 89, 1951-1958.

[43] Thompson T, Poulter D, Miles C, Solmi M, Veronese N, Carvalho AF, Stubbs B, Uc EY (2018) Driving impairment and crash risk in Parkinson disease: A systematic review and meta-analysis. Neurology 91, e906-e916.

[44] Domingos JM, Godinho C, Dean J, Coelho M, Pinto A, Bloem BR, Ferreira JJ (2015) Cognitive impairment in fallrelated studies in Parkinson's disease. J Parkinsons Dis 5, 453-469. 